\title{
Comunicação e arte: o experimento sociológico de Brecht
}

\author{
Celso Frederico \\ Professor da Escola de Comunicações e Artes \\ da Universidade de São Paulo. Bolsista do CNPq. \\ E-mail: celsof@usp.br
}

Resumo: O sucesso comercial da encenação da peça $A$ ópera dos três vinténs fez com que uma poderosa companhia cinematográfica, interessada em filmá-la, procurasse Brecht. Ele aceita a proposta, mas impõe a condição de ser ele o responsável pela adaptação para o cinema. A companhia concorda, então Bertolt Brecht escreve um roteiro suprimindo os elementos comerciais responsáveis pelo sucesso da peça e desenvolvendo ao máximo os aspectos revolucionários do texto. O caso vai parar nos tribunais. Brecht aproveita a ocasião para fazer um debate público sobre as relações entre teatro e cinema, arte e mercadoria e, principalmente, sobre o direito de propriedade da obra artística.

Palavras-chaves: teatro, cinema, mercadoria, propriedade intelectual, comunicação.
Abstract: The commercial success of the staging of The Threepenny Opera caused a powerful film company interested in shooting it to contact Brecht. He accepts the proposal, but imposes a condition: that he would write the adaptation for the cinema. The film company accepts it, and Brecht then writes a screenplay from which he suppresses the commercial elements that had been responsible for the play's success and develops as much as possible the revolutionary aspects of the text. The issue ends up in court. Brecht seizes the occasion to launch a public debate about the relationships between theater and cinema, art and commodity and, mainly, about the property right of the work of art.

Keywords: theater, cinema, commodity, intellectual property, communications.

Em 1930, Bertolt Brecht expressou a consciência do insuperável conflito entre sua visão pedagógica e revolucionária e o que deveria ser a produção artística e a dinâmica do mundo mercantil:

[...] uma inovação que não ameace a função social da engrenagem [...] pode por ela ser apreendida. Mas as que tornam iminente a mudança dessa função e procuram dar à engrenagem uma posição diferente na sociedade [...] esta mudança é renegada por ela. A sociedade absorve por meio da engrenagem apenas o que necessita para sua perpetuação. [...] as engrenagens não pertencem à comunidade: os meios de produção não são ainda a propriedade daqueles que produzem, de modo que o trabalho tem a característica de uma verdadeira mercadoria ${ }^{1}$.

Recebido: 21.5 .2008

Aprovado: 20.6 .2008

1. BRECHT, Bertolt. Notas sobre Mahagonny. In: Teatro dialético. Rio de Janeiro: Civilização Brasileira, 1967. p. 56-57. 
2. Id. Notas sobre A ópera dos três vinténs. In: Teatro dialético. Rio de Janeiro: Civilização Brasileira, 1967. p. 67.

3. BRECHT, Bertolt. El processo de los tres centavos (O processo dos tres vinténs). In: El compromisso en literatura y arte. Barcelona: Península, 1984. Ver também o comentário de José Antonio Pasta Júnior em: Trabalho de Brecht. São Paulo: Ática, 1986 especialmente capítulos II e III.

4. Ibid., p. 148
Essa contradição entre a criação artística e a lógica da mercadoria fora vivida dramática e teatralmente por Brecht em 1928.

O sucesso alcançado por A ópera dos três vinténs fez com que uma companhia cinematográfica se interessasse em comprar-lhe os direitos para filmá-la.

Naquela peça, Brecht havia posto em prática, com sucesso, sua concepção de teatro como divertimento educativo. Para atrair o público, utilizara recursos chamativos ou, em suas palavras, aspectos culinários. Segundo ele, os elementos culinários do teatro devem ser utilizados como iscas que, ao mesmo tempo, atraem o público e criticam seu apetite. Esse recurso fica, portanto, submetido às intenções pedagógicas da arte engajada. O espectador, ávido por iguarias, "vê seus desejos não apenas saciados, mas criticados (vê-se não tanto como sujeito, mas como objeto)" ${ }^{2}$. O teatro, desse modo, atrai o grande público sem deixar de realizar sua função pedagógica.

Brecht aceitou a proposta da empresa cinematográfica, mas introduziu no contrato uma cláusula que lhe garantiu a redação final da adaptação. Escreveu, então, um roteiro que acentuava o caráter revolucionário do enredo em detrimento de seu apelo comercial, de seus elementos culinários.

O escândalo estava armado. O conflito com a empresa cinematográfica, estarrecida com a adaptação, chegou aos tribunais e daí para a imprensa, ocasionando um acalorado debate. Debate no tribunal, envolvendo o conflito entre Brecht e a indústria cinematográfica; debate na imprensa, sobre as relações entre a arte e a indústria. No fundo, uma discussão sobre o direito: a quem pertence, em última análise, uma obra: ao seu autor ou àquele que a comprou? Quem compra tem o direito de desfigurar e até destruir aquilo que foi comprado?

Brecht, percebendo o caráter teatral do processo judicial, armou, de forma premeditada, um escândalo nacional e, sobre ele, escreveu um longo texto: "O processo dos três vinténs" prestados no tribunal, bem como de artigos publicados na imprensa. Os pontos de vista contraditórios são apresentados e Brecht aproveita a ocasião para refletir sobre a justiça, a imprensa, as relações entre a arte e a indústria cultural, entre teatro e cinema e sobre a nova função da arte sob o impacto dos meios de comunicação, já que para ele "a arte é uma forma de comunicação humana e, por isso, depende dos fatores que determinam a comunicação humana em geral".

Trata-se de uma situação nova e inusitada: um autor comunista e, portanto, inimigo da propriedade privada vai ao tribunal defender o direito de propriedade, o direito autoral; um apologista dos novos meios de comunicação e um teórico que entendia a arte como criação coletiva defende um texto teatral contra sua adaptação ao cinema... Consciente da contradição em que se envolvera, Brecht, versado em dialética e, por isso mesmo, atento às possibilidades reveladoras da contradição, não perde essa rara oportunidade para promover um escândalo público. O estardalhaço concebido e planejado por ele foi batizado de experimento sociológico. Tal experimento, diz, ocorre "quando, por medidas apropriadas (procedimento adequado), se provocam e se põem de manifesto as contradições imanentes da sociedade"4. Tratava-se de mostrar os antagonismos sociais, sem solucioná-los. No caso em questão, objetivava-se compreender o funcionamento da cultura. 
Vejamos, em seguida, os termos em que se travou o debate e a argumentação utilizada por Brecht.

Inicialmente, Brecht aproveitou a ocasião para fazer uma ampla crítica do próprio campo das operações - o poder judiciário -, acostumado à rotina de julgar e não refletir sobre o que vem a ser a justiça no mundo capitalista. Se a referência fosse o formalismo jurídico burguês, Brecht teria toda razão em defender o direito de propriedade. Mas, no caso, era a razão, isto é, o direito de um indivíduo, em contradição com os interesses de uma grande companhia que investiu 800 mil marcos na produção de um filme, pagou os direitos de Brecht e, durante todo o processo, quis fazer um acordo financeiro e indenizar o autor pela desfiguração da obra. Brecht recusou o dinheiro oferecido e preferiu abrir uma polêmica pública com uma clara finalidade de educação política. Desde o começo, ele sabia que iria perder, como de fato ocorreu em primeira instância. Não recorreu, pois o custo do processo era milionário e ele não tinha recursos para bancá-lo nem ilusões sobre a justiça. Porém, enquanto decorreu a primeira instância do processo, era a própria justiça que estava, sob os holofotes, sendo publicamente julgada pela encenação pública brechtiana.

O processo, concebido como experimento sociológico, procurou captar certas idéias em ação. A apelação à justiça não foi um ato moral de um autor indignado, mas, ao contrário, uma experiência que tem como problema a própria moral. No decorrer dessa experiência, escreveu Brecht, o tribunal se converte em acusado, já que $o$ direito é corrigido pela realidade. Perante a brutalidade de uma ordem assentada no poder do capital, o formalismo jurídico só poderia ser derrotado. Uma vez mais, a máxima faça-se a justiça e pereça o mundo mostrou ser um formalismo vazio, uma ficção a ser sempre rapidamente corrigida pela realidade.

A derrota do autor foi por ele assim interpretada:

[...] deu-se razão à crua realidade, se pôs de manifesto a mundanidade e a decadência inevitável das idéias burguesas referentes à propriedade (que só pode ser sagrada para os que possuem) e à arte (cujas unidades "orgânicas" têm que ir sendo destruídas cada vez mais) $)^{5}$.

Essa destruição inevitável das unidades orgânicas da arte, promovidas pelos avanços tecnológicos (no caso, o cinema), é o eixo do debate que se travou na imprensa. Uma nova contradição para o autor: confrontar o teatro com as novas formas do fazer artístico.

De um lado, setores do jornalismo cultural defendem a arte verdadeira contra o cinema e as inovações técnicas. Afirmam que a arte não necessita do cinema. Haveria, nesse argumento, um abismo separando a arte verdadeira daquela produzida industrialmente. Esta arte autêntica não estaria "afetada pelas novas possibilidades de comunicação (rádio, cinema, associação de amigos do livro etc.), que, portanto, se vê completamente livre de qualquer influência por parte da indústria moderna"

Segundo esse raciocínio, um autor de peças teatrais não deveria nunca vender os direitos de uma obra para o cinema, já que quem compra tem o direito de fazer o que bem entende com o objeto comprado. Dispor livremente

5. Ibid., p. 108. 6. Ibid., p. 111. 
comunicação \& educação • Ano XIII • Número 3 • set/dez 2008

- o utendi et abudendi - é a máxima que define o que vem a ser a propriedade em termos jurídicos.

Contra aqueles críticos, Brecht argumentou:

[...] aqueles que nos desaconselham empregar esses novos aparatos confirmam a tais aparatos o direito de funcionar mal e faltam à mais clara objetividade: pois se declaram satisfeitos de que somente produzam imundícies. Mas, para nós, nos escamoteiam de antemão os aparatos que necessitamos para nossa produção, pois essa forma de produção irá substituindo cada vez mais a que existiu até agora, nos veremos obrigados a falar com meios cada vez mais condensados, a manifestar o que há de dizer com meios cada vez mais insuficientes ${ }^{7}$.

Essa defesa brechtiana dos aparatos, isto é, da técnica moderna representada pelo cinema, não aceita o papel do teatro como refúgio da verdadeira arte. E isto porque a velha arte já foi subvertida pelo advento do cinema. Nas palavras do autor:

[...] as velhas formas de comunicação não permanecem inalteradas pelas novas formas que surgem. O espectador de cinema lê romances de outro modo. Mas também o que escreve novelas é, por sua vez, espectador do cinema. A tecnificação da produção literária já não é revogável ${ }^{8}$.

Os novos meios de comunicação trouxeram uma forma de apresentação do mundo que colocou em cheque o romance e toda a forma antiga de se fazer arte. Essa tese, que Brecht compartilhava com seu amigo Walter Benjamin, é o ponto de partida de sua tentativa de adequar o teatro à nova realidade e, assim, decretar a caducidade das formas antigas de expressão artística. O romance burguês, um modelo recorrente dos dois amigos, criava um mundo fictício que é expressão direta do modo de ver privado de seu criador. Assim, do mundo real podemos conhecer somente o que é posto pela subjetividade do autor - nunca chegamos, portanto, ao mundo real. O cinema, contrariamente, diz Brecht, é uma criação coletiva que não permite a ninguém expressar-se a si mesmo.

Por outro lado, o emprego dos aparatos marca uma diferença em relação ao romance: este concentra o foco da atenção no personagem; o cinema oferece explicações úteis sobre ações humanas em detalhe. Com isso, ficam em segundo plano o caráter e a vida interior dos personagens. O que interessa, agora, é que o homem aparece como objeto e as relações causais se tornam decisivas.

Portanto, a arte, no caso, a literatura, não pode se subtrair ao progresso no campo da comunicação: ela precisa do cinema nesse momento em que se realiza uma transformação funcional da arte em uma disciplina pedagógica.

Abrir mão dos novos meios significa para Brecht reivindicar uma liberdade e um direito fora dos meios de produção. Mas fora desses meios não existe nem liberdade nem direito. A condição de produtor é a mesma para o artista e para o operário. O operário é um ser livre, já que não é obrigado a vender sua força de trabalho para esse ou aquele patrão. Há, entre eles, uma igualdade de direitos. Porém, sem o acesso aos meios de produção, o operário não pode produzir e sobreviver. De nada lhe vale sua liberdade e igualdade de direitos

7. Ibid., p. 109 8. Ibid., p. 109 que compartilha com o capitalista. Portanto, conclui Brecht, para o artista e para o operário trata-se de reivindicar a socialização dos meios de produção. 
Brecht, além de criticar a tese de que a arte não necessita do cinema, também critica a tese oposta: o cinema necessita da arte. O cinema, segundo essa tese, é uma indústria que produz artigos estimulantes e, por isso, precisa da arte para enobrecê-los, para dar-lhes um valor verdadeiramente artístico.

Ele refuta essa tese, pois, a antiga arte, baseada na experiência, morreu. Os aparatos abrem novas possibilidades para o fazer artístico. Pode-se, com eles, fixar comportamentos de forma visível ou mostrar processos simultâneos e, assim, fixar o comportamento mútuo dos homens. A antiga forma artística de reprodução da realidade pouco afirma sobre o novo momento da realidade. Em suas palavras:

Uma fotografia da fábrica Krupp ou da A.E.G. quase nada prova destas instituições. A realidade autêntica resvala e cai no funcional. A concretização das relações humanas, a fábrica, digamos, não reproduz já essas últimas. É, pois, em realidade, "algo a construir", algo "artificial", algo "posto".

Com isso, Brecht defende a necessidade de uma nova arte com uma função bem diferente da antiga - não mais reproduzir, mas mostrar por meios artificiais o processo de construção da realidade.

Seja lá o que for a arte, ela tornou-se mercadoria. Este é mais um tema discutido por Brecht. Perante a forma mercantil, duas posições se cristalizaram durante o processo judicial.

Para alguns críticos, a arte tornou-se uma mercadoria, incidentalmente, apenas no momento em que ela se põe em circulação, o que não alteraria o seu verdadeiro caráter. Caberia, portanto, à arte verdadeira libertar-se dessa situação. Ora, diz Brecht, quem pensa assim não percebe o poder transformador da condição mercantil. Se a produção, no capitalismo, é uma forma de exploração, como deixar a arte fora desse processo e acreditar que ela, sozinha, escape de um destino inexorável? Podemos ouvir aqui o eco do argumento do Manifesto do Partido Comunista, quando se refere à "força descomunal daquele processo revolucionário que arrasta todas as coisas deste mundo dentro da circulação mercantil”10.

Outros críticos, contrariamente, afirmavam o caráter necessariamente mercantil do cinema e lamentam esse fato - a condição de mercadoria reservada também à arte. Contra eles, Brecht argumenta que o fato de entrar na circulação mercantil pode ser favorável a uma obra de arte. Por quê? Aqui aparecem dois temas cruzados.

A frase: a obra de arte é mercadoria, diz Brecht, seria uma afirmação tautológica se a obra não contivesse uma função. Mesmo sob o domínio da forma mercantil, ela cumpre uma missão progressista: de um lado, põe fim ao vínculo entre arte e religião e, de outro, sepulta a velha ideologia burguês-humanista presente na antiga concepção de arte baseada no indivíduo. Enfim: a produção mercantil é progressista, pois, em sua dinâmica ascendente, faz aflorar a contradição. Ela rompe com o passado e com a própria ideologia burguesa e anuncia o futuro que virá (a forma de produção burguesa reduz a escombros a ideologia burguesa).

Por outro lado, a mercantilização é uma tendência geral do capitalismo que acompanha e incentiva o progresso tecnológico. Essa tendência é um momento progressista que será, futuramente, superado quando a técnica estiver em boas mãos. Aí, a nova função da arte poderá realizar-se integralmente.

9. Ibid., p. 113.

10. Ibid., p. 118. 
11. ADORNO, Theodor W.; HORKHEIMER, Max. Dialética do esclarecimento: fragmentos filosóficos. 7. ed. Rio de Janeiro: Jorge Zahar, 1997.

12. Cf. FrEDERICO, Celso. Brecht e a teoria do rádio. Revista Estudos Avançados, n. 60, 2007.

13. BRECHT, Bertolt. Poemas. Tradução de Paulo César de Souza. São Paulo: Ed. 34, 2000. p. 290.
Essas idéias paradoxais sobre o caráter progressista da mercantilização da arte, defendidas de forma idêntica por dois autores comunistas - Bertolt Brecht e Walter Benjamin -, expressam as esperanças revolucionárias de um período determinado. Com a derrota do ciclo revolucionário na Europa, os resultados nocivos da mercantilização logo se fizeram visíveis. Esse é o contexto em que Adorno, na obra Dialética do esclarecimento: fragmentos filosóficos ${ }^{11}$, irá se voltar diretamente contra o ensaio de Benjamin, A obra de arte na era de sua reprodutibilidade técnica. O famoso e problemático texto sobre a indústria cultural foi a resposta final de Adorno a Benjamin, mas os argumentos também se dirigem contra Brecht.

Depois de 1933, Brecht, no exílio, amadurece sua reflexão sobre o complexo cultural: o esquematismo de suas peças didáticas, que havia marcado sua produção nos anos 1920, é deixado de lado e a própria concepção teatral, lentamente decantada, dirige-se para a defesa de um teatro épico e, em seguida, para um teatro dialético.

Nesse novo momento, Brecht repensa não só suas idéias sobre a mercantilização da arte, como também sobre a função do teatro na modernidade, refinando assim suas posições quanto à função pedagógica da arte.

As posições defendidas até então tinham como pressuposto um amplo movimento social na retaguarda. É nesse contexto que Brecht escreveu suas peças didáticas, sua teoria sobre o rádio, ${ }^{12} \mathrm{e}$ encenou publicamente o seu experimento sociológico. Mas como é possível, numa conjuntura marcada pelo terror nazista, manter em estado de tensão máxima a oposição entre a nova função pretendida pela arte e as engrenagens do mundo capitalista?

Tempos depois, ainda no exílio, Brecht vive uma nova relação com a indústria cultural. Seu poema Hollywood expressa em tom melancólico a condição do artista no mundo das mercadorias:

A cada manhã, para ganhar meu pão,

Vou ao mercado onde mentiras são compradas.

Esperançoso,

Tomo lugar entre os vendedores ${ }^{13}$.

\section{REFERÊNCIAS BIBLIOGRÁFICAS}

BRECHT, Bertolt. Notas sobre Mahagonny. In: Teatro dialético. Rio de Janeiro: Civilização Brasileira, 1967.

. Notas sobre A ópera dos três vinténs. In: Teatro dialético. Rio de Janeiro: Civilização Brasileira, 1967.

. El processo de los tres centavos (O processo dos três vinténs). In: El compromisso en literatura y arte. Barcelona: Península, 1984.

. Poemas. Tradução de Paulo César de Souza. São Paulo: Ed. 34, 2000.

FREDERICO, Celso. Brecht e a teoria do rádio. Revista Estudos Avançados, n. 60, 2007. 